\title{
USO DA FERTIRRIGAÇÃO E TEORES DE MACRONUTRIENTES EM PLANTA DE PIMENTÃ ${ }^{1}$
}

\author{
FRANCISCO F. N. MARCUSSI ${ }^{2}$
}

RESUMO: Este estudo teve o objetivo de determinar os teores de macronutrientes (N, P, K, Ca, Mg e S) nos diferentes órgãos do híbrido de pimentão Elisa, sob fertirrigação e ambiente protegido, por meio de coletas de plantas durante o ciclo. Ao final do experimento, obtiveram-se os teores dos macronutrientes no fruto, folha, caule, raiz e na planta como um todo, em cada etapa de crescimento. A fertilização no ciclo estudado, 140 dias, foi feita via irrigação localizada (gotejamento). O experimento foi desenvolvido nas dependências do Departamento de Recursos Naturais - Ciência do Solo, FCAUNESP, Câmpus de Botucatu - SP, e constou de oito tratamentos (épocas de coleta de planta: 0; 20; 40; 60; 80; 100; 120 e 140 dias após o transplante das mudas) e quatro repetições, sendo cada repetição formada por quatro plantas. Os resultados mostram que os teores de macronutrientes encontrados na planta de pimentão seguem, na média, a seguinte ordem decrescente: $\mathrm{K}\left(39,9 \mathrm{~g} \mathrm{~kg}^{-1}\right)>\mathrm{N}\left(28,3 \mathrm{~g} \mathrm{~kg}^{-1}\right)$ $>\mathrm{Ca}\left(12,8 \mathrm{~g} \mathrm{~kg}^{-1}\right)>\operatorname{Mg}\left(5,9 \mathrm{~g} \mathrm{~kg}^{-1}\right)>\mathrm{S}\left(4,1 \mathrm{~g} \mathrm{~kg}^{-1}\right)>\mathrm{P}\left(3,7 \mathrm{~g} \mathrm{~kg}^{-1}\right)$.

PALAVRAS-CHAVE: gotejamento, concentrações de macronutrientes, Capsicum annuum L.

\section{FERTIGATION APPLICATION AND MACRONUTRIENTS CONCENTRATIONS IN PLANT OF BELL PEPPER}

\begin{abstract}
In this study, it was aimed the determination of macronutrients contents ( N, P, K, Ca, $\mathrm{Mg}$ and $\mathrm{S}$ ) in different organs of the hybrid of bell pepper Elisa, under fertigation and protected atmosphere, through eight times of plant extraction. At the end of the experiment it was obtained the contents of macronutrients in the fruit, leaf, stem and root and in the plant as a whole, in each growth stage. The fertilization in the studied cycle, 140 days, was done through localized fertigation (drip system). The experiment was developed in the Department of Natural Resources - Soil Science, FCAUNESP, Botucatu - SP, Brazil. The experiment consisted of eight treatments (time of plant extraction: $0 ; 20 ; 40 ; 60 ; 80 ; 100 ; 120$, and 140 days after the transplant of the seedlings) and four repetitions, being each repetition formed by four plants. The macronutrients contents found in the plant have the following decreasing order: $\mathrm{K}\left(39,9 \mathrm{~g} \mathrm{~kg}^{-1}\right)>\mathrm{N}\left(28,3 \mathrm{~g} \mathrm{~kg}^{-1}\right)>\mathrm{Ca}\left(12,8 \mathrm{~g} \mathrm{~kg}^{-1}\right)>\mathrm{Mg}\left(5,9 \mathrm{~g} \mathrm{~kg}^{-1}\right)>\mathrm{S}$ $\left(4,1 \mathrm{~g} \mathrm{~kg}^{-1}\right)>\mathrm{P}\left(3,7 \mathrm{~g} \mathrm{~kg}^{-1}\right)$.
\end{abstract}

KEYWORDS: drip irrigation, macronutrients concentration, Capsicum annuum L.

\section{INTRODUÇÃO}

O manejo de fertilizantes em agricultura irrigada, juntamente com o conhecimento das demandas de nutrientes durante o ciclo das culturas contribuem para uma eficiência da adubação. Em alguns países, como os Estados Unidos, Israel e Itália, a fertirrigação tornou-se uma técnica de uso generalizado, principalmente com o desenvolvimento de modernos sistemas de irrigação e pela qualidade dos fertilizantes líquidos. Com a difusão de novas tecnologias em irrigação, a introdução de fertilizantes líquidos no mercado, o custo crescente da mão-de-obra, a necessidade de aumentar a eficiência de utilização dos insumos e implementar a produtividade dos sistemas de produção agrícola,

\footnotetext{
${ }^{1}$ Fomentado pela FAPESP.

${ }^{2}$ Eng $^{\mathrm{o}}$ Agrônomo, M.Sc., Doutorando em Engenharia Hidráulica e Saneamento, Av. Trabalhador Sãocarlense, 400, EESC/USP, Departamento de Hidráulica e Saneamento, São Carlos - SP, marcussi@ sc.usp.br

Recebido pelo Conselho Editorial em: 4-6-2003

Aprovado pelo Conselho Editorial em: 25-8-2005
} 
especialmente em áreas de cerrado e do trópico semi-árido, abrem grandes perspectivas à utilização dessa tecnologia (COELHO, 1994).

Uma das mais importantes vantagens da fertirrigação está relacionada com a eficiência de absorção de nutrientes pela planta, isso porque oferece à planta o nutriente prontamente disponível na solução do solo para ser absorvido, provocando necessidade crescente de obter parâmetros de avaliação do estado nutricional da planta a fim de corrigir possíveis deficiências ou toxidez. FRIZZONE et al. (1994), também citam a fertirrigação como sendo o melhor instrumento para manter um teor adequado de nutrientes na solução do solo e, conseqüentemente, uma boa nutrição da planta.

O pimentão (Capsicum annuum L.) destaca-se, entre as solanáceas, por ser consumido em grande quantidade, além de possuir importância econômica, no Brasil e exterior, principalmente nos Estados Unidos, México, Itália, Japão e Índia (SILVA, 1998), sendo, portanto, a tecnologia empregada na produção de pimentão cada vez mais apurada, buscando reduzir custos e aumentar a produtividade, sendo que o emprego da fertirrigação pode contribuir na busca desses objetivos. COELHO (1994) cita que não só o conhecimento do comportamento dos macronutrientes do solo, em relação a sua mobilidade, mas também a exigência nutricional de uma cultura durante o seu ciclo são fatores importantes a considerar no manejo dos fertilizantes, na fertirrigação. Segundo MALAVOLTA (1993), o interesse em conhecer os teores de nutrientes se acopla à avaliação do estado nutricional por meio da variação na composição de órgãos representativos. O conhecimento da exigência nutricional e da concentração dos nutrientes por meio de órgãos representativos nas plantas é importante para estabelecer as quantidades de nutrientes a serem aplicadas por meio dos fertilizantes, obtendo, assim, melhores rendimentos.

O teor de nutrientes nas plantas varia de acordo com seu desenvolvimento, sendo distinto com a floração, formação e crescimento dos frutos. A correção do solo e a adubação de hortaliças são, muitas vezes, feitas com doses acima das recomendadas, havendo mais a preocupação em evitar deficiências; assim fazendo, incorre-se no perigo dos excessos prejudiciais, além dos desperdícios. Portanto, é importante conhecer o teor de macronutrientes na planta, o modo de avaliar seu respectivo estado nutricional e o momento certo de aplicar esses nutrientes, de acordo com a sua respectiva fase de desenvolvimento (RAIJ, 1993).

As curvas de resposta das culturas podem ser diferentes não só entre órgãos vegetativos e reprodutivos, mas também entre os componentes da produção colhida (MARSCHNER, 1995). Esse fato remete à importância do conhecimento da concentração do nutriente em cada órgão da planta, de modo a obter parâmetros para avaliação. GUPTA (2001) ressalta a importância da amostragem da parte apropriada da planta e o estágio de crescimento para a avaliação do estado nutricional.

Nem a aparência da cultura, nem as evidências visuais disponíveis podem levar a uma diagnose confiável na identificação de deficiência ou excesso de macronutrientes (MAGALHÃES, 1988). Nesses casos, a análise química do tecido vegetal torna-se o procedimento recomendado para posterior comparação com os valores críticos de concentrações dos macronutrientes. Nota-se, portanto, que a concentração de nutrientes pela planta fornece informações importantes para o conhecimento das proporções de nutrientes a serem aplicadas durante a fertirrigação.

No pimentão, existem poucos estudos a respeito das concentrações de macronutrientes na planta para avaliar sua deficiência ou suficiência. Esses estudos são úteis na avaliação do seu estado nutricional: isso porque, quanto maior a capacidade da parte da planta em acumular um nutriente, maiores serão as diferenças na concentração desse nutriente em resposta a taxas variáveis de adubação.

Neste trabalho, teve-se o objetivo de determinar os teores de macronutrientes $(\mathrm{N}, \mathrm{P}, \mathrm{K}, \mathrm{Ca}, \mathrm{Mg}$ e S) nos diferentes órgãos do híbrido de pimentão Elisa, sob fertirrigação em ambiente protegido, por meio de coletas de plantas durante o ciclo. Ao final do experimento, obtiveram-se os teores dos 
macronutrientes no fruto, folha, caule, raiz e na planta como um todo, em cada etapa de crescimento, buscando dados para comparação de análise de nutrientes de tecidos, visando ao melhor gerenciamento de fertirrigação para a planta de pimentão.

\section{MATERIAL E MÉTODOS}

O experimento foi conduzido em túnel plástico com $7 \mathrm{~m}$ de largura, $20 \mathrm{~m}$ de comprimento e 2,5 m de altura, no Departamento de Recursos Naturais/Ciência do Solo, pertencente à Faculdade de Ciências Agronômicas - UNESP, Botucatu - SP (2251'S, 48²6'W e 786 m de altitude).

Os vasos que receberam as mudas foram preenchidos com $29 \mathrm{~L}$ de Latossolo Vermelho-Escuro, textura arenosa, cujas características químicas, no momento do transplante das mudas, encontram-se na Tabela 1.

TABELA 1. Análise química do solo no momento do transplantio das mudas de pimentão híbrido Elisa.

\begin{tabular}{|c|c|c|c|c|c|c|c|c|c|}
\hline $\mathrm{pH}$ & M.O. & $\mathrm{P}$ & $\mathrm{H}+\mathrm{Al}$ & $\mathrm{K}^{+1}$ & $\mathrm{Ca}^{+2}$ & $\mathrm{Mg}^{+2}$ & SB & CTC & V \\
\hline $\mathrm{CaCl}_{2}$ & $\mathrm{~g} \mathrm{dm}^{-3}$ & $\mathrm{mg} \mathrm{dm}^{-3}$ & -------- & - & $\mathrm{nmol}_{\mathrm{c}}$ & de terı & ----. & --------- & $(\%)$ \\
\hline 6,0 & 20 & 71 & 21 & 3,7 & 59 & 27 & 90 & 112 & 81 \\
\hline
\end{tabular}

Para simular um sistema de irrigação localizada, para cada vaso, foi adaptada uma garrafa tipo PET de $2 \mathrm{~L}$, que foi pendurada de cabeça para baixo, sendo a parte superior (fundo da garrafa) cortada para permitir colocar água e também a solução contendo os fertilizantes. A extremidade inferior (tampa) foi perfurada, sendo colocada uma mangueira, cuja extremidade possuía um gotejador que controlava a vazão. O delineamento experimental foi em blocos casualizados, composto de oito períodos (tratamentos) de amostragens de plantas (híbrido de pimentão Elisa): tempo zero (estágio de muda, no momento do transplantio); 20; 40; 60; 80; 100; 120 e 140 dias após o transplantio da muda e quatro repetições (com quatro plantas em cada repetição). Para diminuir os problemas de variação genética do material estudado, cada vaso continha duas plantas, sendo cada parcela experimental composta por dois vasos e, portanto, cada repetição formada por quatro plantas, totalizando, no experimento, 56 vasos com duas plantas cada.

Após o transplante, foram realizados os tratos culturais, de acordo com a necessidade das plantas, sendo as desbrotas executadas logo após o surgimento dos ramos laterais. As pulverizações foram realizadas conforme as especificações técnicas e a aplicação de água, via irrigação localizada, foi feita diariamente, conforme as necessidades das plantas, por meio de um tanque Classe A e o Kc da cultura.

A primeira aplicação da fertirrigação foi feita 54 dias após o transplante, uma vez que, por meio de diagnose, identificou-se que a adubação básica (principalmente o uso de composto orgânico) estava fornecendo nutrientes de forma apropriada às plantas, sendo que a freqüência da fertirrigação foi de três em três dias, totalizando 29 aplicações. No total, foram aplicados 5,951 g de nitrogênio; 3,835 $\mathrm{g}$ de potássio, e 5,776 g de cálcio por planta. Da primeira até a terceira aplicação, aplicaram-se apenas $\mathrm{N}$ e $\mathrm{Ca}$, utilizando-se de $1,9 \mathrm{~g}$ de $\mathrm{CaNO}_{3}$ por planta, por aplicação, diluído em $250 \mathrm{~mL}$ de água. Em seguida, a partir da quarta aplicação, iniciou-se a aplicação de K e aumentou-se a dosagem de nitrogênio, acrescentando-se $0,82 \mathrm{~g}$ de $\mathrm{KNO}_{3}$ por planta, por aplicação, diluído em $250 \mathrm{~mL}$ de água. Fizeram-se aplicações de boro $(0,299 \mathrm{mg})$ e manganês $(0,264 \mathrm{mg})$, usando-se bórax e sulfato de manganês, respectivamente.

A cada 20 dias, as plantas de pimentão eram coletadas e separadas em raiz, caule, folha e fruto. Posteriormente, esse material foi lavado com água destilada para secagem em estufa $\left(65{ }^{\circ} \mathrm{C}\right)$, moído e analisado quimicamente, segundo metodologia citada por BATAGLIA (1991). Na análise química, foi 
determinada a concentração de macronutrientes (N, P, K, Ca, Mg e S) em cada órgão da planta, sendo os resultados submetidos à análise de variância, com teste $\mathrm{F}$, e as médias comparadas pelo teste de Tukey, a 5\% de probabilidade.

\section{RESULTADOS E DISCUSSÃO}

Nas Tabelas 2; 3; 4; 5 e 6, são apresentados os resultados das concentrações de macronutrientes no fruto, folha, caule, raiz e na planta inteira, respectivamente. Os macronutrientes obtiveram maior concentração aos 60 dias após o transplantio (DAT), quando a planta apresentava apenas frutos em formação e nenhum fruto comercial, ou seja, para a planta de pimentão, a concentração de macronutrientes tende a ser inversamente proporcional ao crescimento dos frutos.

O macronutriente que apresentou maior concentração no fruto (Tabela 2), foi o fósforo, com média de 33,3 $\mathrm{g} \mathrm{kg}^{-1}$ de matéria seca durante o período de 60 a 140 DAT, seguido pelo nitrogênio, com média de $33,2 \mathrm{~g} \mathrm{~kg}^{-1}$. O cálcio, o fósforo, o enxofre e o magnésio obtiveram, respectivamente, concentrações médias de 5,1; 4,5; 3,9 e 3,3 $\mathrm{g} \mathrm{kg}^{-1}$. Com esses resultados, verifica-se que, em média, de 60 a 140 DAT, o potássio contribuiu com 39,94\% da concentração total de macronutrientes no fruto da planta de pimentão, seguido pelo nitrogênio com 39,88\%, cálcio com 6,07\%, fósforo com 5,39\%, enxofre com 4,70\% e magnésio com 4,01\%. FURLANI et al. (1978), utilizando-se da variedade Mônica, acharam as seguintes concentrações de macronutrientes no fruto do pimentão: $21,8 \mathrm{~g} \mathrm{~kg}^{-1} \mathrm{de}$ $\mathrm{N} ; 4,1 \mathrm{~g} \mathrm{~kg}^{-1}$ de $\mathrm{P} ; 9,8 \mathrm{~g} \mathrm{~kg}^{-1}$ de $\mathrm{K} ; 1,1 \mathrm{~g} \mathrm{~kg}^{-1}$ de Ca; $1,2 \mathrm{~g} \mathrm{~kg}^{-1}$ de $\mathrm{Mg}$, e 2,5 $\mathrm{g} \mathrm{kg}^{-1} \mathrm{de} \mathrm{S}$. MALAVOLTA et al. (1997) dizem que, dentre os principais nutrientes ligados ao aumento da produtividade, o K é, em média, o segundo elemento mais abundante na matéria seca das plantas quando se consideram os macronutrientes essenciais. Segundo MARSCHNER (1995), o crescimento do fruto envolve não somente o redirecionamento de assimilados e minerais para o desenvolvimento desse órgão, mas também a remobilização de nutrientes de outros tecidos da planta.

Em relação à coleta inicial, aos 60 DAT, observa-se que, aos 80 DAT, o nitrogênio perdeu $43 \%$ de sua concentração no fruto, e o cálcio foi o nutriente que mais perdeu concentração, chegando, aos 80 DAT, com apenas $22 \%$ da concentração obtida aos 60 DAT; esse período de grande perda de concentração de macronutrientes por parte dos frutos deve-se à grande quantidade de frutos em ponto de colheita, reiterando que frutos mais desenvolvidos possuem menor concentração de macronutrientes em relação a frutos jovens. A maior concentração de macronutrientes no fruto da planta de pimentão ocorreu aos 60 DAT. O N, Ca, Mg e S diferem, significativamente, nos períodos analisados. Ressaltase que, em todo o período de estudo (140 dias), as plantas não apresentaram deficiência nutricional ou qualquer outro problema que poderia afetar a disponibilidade de nutrientes das plantas, já que a fertilização era feita via fertirrigação localizada, disponibilizando, portanto, os nutrientes prontamente à solução do solo para serem absorvidos.

TABELA 2. Teores de macronutrientes no fruto de pimentão aos $60 ; 80 ; 100 ; 120$ e 140 dias após o transplantio de mudas.

\begin{tabular}{cccccc}
\hline Nutriente/ & 60 & 80 & 100 & 120 & 140 \\
\cline { 2 - 6 } Tempo & \multicolumn{5}{c}{$\mathrm{g} \mathrm{kg}^{-1}$} \\
\hline $\mathrm{N}$ & $50,0 \mathrm{a}^{(1)}$ & $28,3 \mathrm{bc}$ & $24,5 \mathrm{c}$ & $29,0 \mathrm{bc}$ & $34,3 \mathrm{~b}$ \\
$\mathrm{P}$ & $40,8 \mathrm{a}$ & $32,0 \mathrm{~b}$ & $29,8 \mathrm{~b}$ & $35,0 \mathrm{ab}$ & $28,8 \mathrm{~b}$ \\
$\mathrm{~K}$ & $5,2 \mathrm{a}$ & $2,9 \mathrm{~b}$ & $2,8 \mathrm{~b}$ & $3,6 \mathrm{~b}$ & $5,2 \mathrm{a}$ \\
$\mathrm{Ca}$ & $6,1 \mathrm{a}$ & $2,1 \mathrm{~d}$ & $2,4 \mathrm{~cd}$ & $2,8 \mathrm{bc}$ & $3,3 \mathrm{~b}$ \\
$\mathrm{Mg}$ & $7,7 \mathrm{a}$ & $2,4 \mathrm{~d}$ & $3,0 \mathrm{~cd}$ & $4,2 \mathrm{bc}$ & $5,1 \mathrm{~b}$ \\
$\mathrm{~S}$ & $10,3 \mathrm{a}$ & $2,3 \mathrm{c}$ & $3,0 \mathrm{c}$ & $3,5 \mathrm{c}$ & $6,3 \mathrm{~b}$ \\
\hline
\end{tabular}

${ }^{(1)}$ Médias seguidas pela mesma letra, na linha, não diferem estatisticamente, pelo teste de Tukey $(0,05)$. 
$\mathrm{Na}$ folha da planta de pimentão, dentre os macronutrientes, o potássio foi o que apareceu com maior concentração, em todo o ciclo estudado da cultura, com média de $50,5 \mathrm{~g} \mathrm{~kg}^{-1}$ de matéria seca (Tabela 3), do transplantio até 140 DAT, seguido pelo nitrogênio, com média de $37,7 \mathrm{~g} \mathrm{~kg}^{-1}$, cálcio com 24,0 $\mathrm{g} \mathrm{kg}^{-1}$, magnésio com 9,6 $\mathrm{g} \mathrm{kg}^{-1}$, enxofre com 4,8 $\mathrm{g} \mathrm{kg}^{-1}$ e o fósforo com 4,4 $\mathrm{g} \mathrm{kg}^{-1}$. Porém, o potássio apareceu em maior concentração aos 20; 40 e 60 DAT, o nitrogênio aos 40 e 140 DAT, o fósforo e o enxofre no momento do transplantio (tempo 0), o cálcio aos 120 DAT e o magnésio aos 100 e 120 DAT. Os resultados mostram que, em média, do transplantio até 140 DAT, o potássio contribuiu com 38,60\% da concentração total de macronutrientes na folha da planta de pimentão, seguido pelo nitrogênio com 28,76\%, cálcio com 18,33\%, magnésio com 7,29\%, enxofre com 3,69\% e o fósforo com 3,32\%. Observa-se que o nitrogênio obteve maior concentração na folha, aos 40 DAT, o que representou 54\% a mais em sua concentração em relação ao tempo 0 (no transplantio de mudas). Nota-se que o fósforo foi o único nutriente que obteve grande diferença no tempo $0\left(15,5 \mathrm{~g} \mathrm{~kg}^{-1}\right) \mathrm{em}$ relação à menor concentração encontrada, que foi aos 80 DAT $\left(1,4 \mathrm{~g} \mathrm{~kg}^{-1}\right)$, ou seja, o fósforo na folha perdeu 90,97\% de sua concentração aos 80 DAT, tomando-se como base o tempo 0. Segundo NASCIMENTO JUNIOR (1998), os teores de macronutrientes na folha da planta de pimentão (cultivar Magali), aos 67 DAT, são, em g kg-1 : 50,6 de N; 40,2 de K; 18,8 de Ca e 6,8 de Mg.

TABELA 3. Teores de macronutrientes na folha da planta de pimentão no transplantio: (0); 20; 40; 60; $80 ; 100 ; 120$ e 140 dias após o transplantio de mudas.

\begin{tabular}{crrrrrrrc}
\hline \multirow{2}{*}{$\begin{array}{c}\text { Nutriente/ } \\
\text { Tempo }\end{array}$} & 0 & 20 & 40 & 60 & 80 & 100 & 120 & 140 \\
\cline { 2 - 8 } & \multicolumn{7}{c}{$\mathrm{g} \mathrm{kg}^{-1}$} \\
$\mathrm{~N}$ & $21,0 \mathrm{c}^{(1)}$ & $37,0 \mathrm{~b}$ & $46,3 \mathrm{a}$ & $39,0 \mathrm{~b}$ & $37,3 \mathrm{~b}$ & $37,3 \mathrm{~b}$ & $37,8 \mathrm{~b}$ & $45,8 \mathrm{a}$ \\
$\mathrm{P}$ & $15,5 \mathrm{a}$ & $4,8 \mathrm{~b}$ & $3,7 \mathrm{c}$ & $2,6 \mathrm{~d}$ & $1,4 \mathrm{e}$ & $1,7 \mathrm{e}$ & $2,5 \mathrm{~d}$ & $2,7 \mathrm{~d}$ \\
$\mathrm{~K}$ & $52,0 \mathrm{~b}$ & $60,0 \mathrm{a}$ & $58,8 \mathrm{a}$ & $58,8 \mathrm{a}$ & $40,3 \mathrm{~d}$ & $41,5 \mathrm{~d}$ & $49,0 \mathrm{bc}$ & $44,0 \mathrm{~cd}$ \\
$\mathrm{Ca}$ & $20,0 \mathrm{c}$ & $22,0 \mathrm{c}$ & $20,5 \mathrm{c}$ & $22,0 \mathrm{c}$ & $20,8 \mathrm{c}$ & $27,5 \mathrm{~b}$ & $31,8 \mathrm{a}$ & $27,5 \mathrm{~b}$ \\
$\mathrm{Mg}$ & $6,1 \mathrm{~d}$ & $10,7 \mathrm{a}$ & $10,2 \mathrm{ab}$ & $10,2 \mathrm{ab}$ & $9,0 \mathrm{bc}$ & $11,1 \mathrm{a}$ & $11,3 \mathrm{a}$ & $7,9 \mathrm{c}$ \\
$\mathrm{S}$ & $6,5 \mathrm{a}$ & $4,1 \mathrm{de}$ & $5,6 \mathrm{~b}$ & $5,3 \mathrm{bc}$ & $3,3 \mathrm{f}$ & $3,5 \mathrm{ef}$ & $4,8 \mathrm{~cd}$ & $5,7 \mathrm{~b}$ \\
\hline
\end{tabular}

${ }^{(1)}$ Médias seguidas pela mesma letra, na linha, não diferem estatisticamente, pelo teste de Tukey $(0,05)$.

No caule da planta de pimentão, o macronutriente que apareceu em maior concentração foi o potássio, em todo o ciclo estudado da cultura, com média de $41,7 \mathrm{~g} \mathrm{~kg}^{-1}$ de matéria seca (Tabela 4), do transplantio até 140 DAT, seguido pelo nitrogênio, com média de $18,3 \mathrm{~g} \mathrm{~kg}^{-1}$, cálcio com $9,3 \mathrm{~g} \mathrm{~kg}^{-1}$, magnésio com 5,6 $\mathrm{g} \mathrm{kg}^{-1}$, enxofre com 4,1 $\mathrm{g} \mathrm{kg}^{-1}$ e o fósforo com 2,4 $\mathrm{g} \mathrm{kg}^{-1}$. Os resultados apontam que, em média, do transplantio até 140 DAT, o potássio contribuiu com 51,26\% da concentração total de macronutrientes no caule da planta de pimentão, seguido pelo nitrogênio com 22,50\%, cálcio com $11,40 \%$, magnésio com $6,90 \%$, enxofre com $5,01 \%$ e o fósforo com 2,91\%. Observa-se que o nitrogênio obteve maior concentração no caule, aos 20 DAT, o que representou 54\% a mais em sua concentração em relação ao tempo 0 (no transplantio de mudas). Nota-se que o fósforo, no caule, assim como na folha, foi o único nutriente que obteve grande diferença no tempo $0\left(6,7 \mathrm{~g} \mathrm{~kg}^{-1}\right) \mathrm{em}$ relação à menor concentração encontrada, que foi aos $80 \mathrm{DAT}\left(0,8 \mathrm{~g} \mathrm{~kg}^{-1}\right)$, ou seja, o fósforo, no caule, perdeu $88,06 \%$ de sua concentração aos 80 DAT, tomando-se como base o tempo 0.

Os resultados da Tabela 5 mostram que o macronutriente que alcançou a maior concentração na raiz da planta de pimentão, foi o nitrogênio, em todo o ciclo estudado da cultura, com média de $23,0 \mathrm{~g} \mathrm{~kg}^{-1}$ de matéria seca, do transplantio até 140 DAT, seguido de perto pelo potássio, com média de 22,9 $\mathrm{g} \mathrm{kg}^{-1}$, cálcio com 7,8 $\mathrm{g} \mathrm{kg}^{-1}$, magnésio com 3,6 $\mathrm{g} \mathrm{kg}^{-1}$, enxofre com 3,1 g kg-1 e o fósforo com $2,7 \mathrm{~g} \mathrm{~kg}^{-1}$. Observa-se que, em média, do transplantio até 140 DAT, o nitrogênio contribuiu com $36,51 \%$ da concentração total de macronutrientes na raiz da planta de pimentão, seguido de perto pelo potássio com $36,36 \%$, cálcio com $12,33 \%$, magnésio com $5,66 \%$, enxofre com $4,89 \%$ e o fósforo com 
4,25\%. Observa-se que o nitrogênio obteve maior concentração na raiz aos 20 DAT, representando $40 \%$ a mais em sua concentração em relação ao tempo 0 (no transplantio de mudas). Nota-se que o fósforo, na raiz, assim como no caule e na folha, foi o único nutriente que obteve grande diferença no tempo $0\left(7,6 \mathrm{~g} \mathrm{~kg}^{-1}\right)$ em relação à menor concentração encontrada, que foi aos 60 DAT $\left(1,1 \mathrm{~g} \mathrm{~kg}^{-1}\right), \mathrm{ou}$ seja, o fósforo, no caule, perdeu $86,84 \%$ de sua concentração aos 60 DAT, tomando-se como base o tempo 0 .

TABELA 4. Teores de macronutrientes no caule da planta de pimentão no transplantio: (0); 20; 40; 60; 80; 100; 120 e 140 dias após o transplantio de mudas.

\begin{tabular}{ccccccccc}
\hline Nutriente/ & 0 & 20 & 40 & 60 & 80 & 100 & 120 & 140 \\
\cline { 2 - 8 } Tempo & \multicolumn{7}{c}{$\mathrm{g} \mathrm{kg}^{-1}$} \\
\hline $\mathrm{N}$ & $12,0 \mathrm{~d}^{(1)}$ & $26,0 \mathrm{a}$ & $25,5 \mathrm{a}$ & $20,0 \mathrm{~b}$ & $13,8 \mathrm{~cd}$ & $16,0 \mathrm{c}$ & $16,8 \mathrm{bc}$ & $16,5 \mathrm{c}$ \\
$\mathrm{P}$ & $6,7 \mathrm{a}$ & $2,2 \mathrm{bc}$ & $2,5 \mathrm{~b}$ & $1,9 \mathrm{~cd}$ & $0,8 \mathrm{f}$ & $1,3 \mathrm{ef}$ & $1,7 \mathrm{de}$ & $2,0 \mathrm{~cd}$ \\
$\mathrm{~K}$ & $49,0 \mathrm{~b}$ & $58,0 \mathrm{a}$ & $51,3 \mathrm{~b}$ & $50,3 \mathrm{~b}$ & $36,3 \mathrm{c}$ & $33,5 \mathrm{~cd}$ & $29,3 \mathrm{de}$ & $26,3 \mathrm{e}$ \\
$\mathrm{Ca}$ & $13,0 \mathrm{a}$ & $13,0 \mathrm{a}$ & $8,3 \mathrm{bcd}$ & $7,0 \mathrm{~cd}$ & $6,8 \mathrm{~d}$ & $7,8 \mathrm{~cd}$ & $8,8 \mathrm{bc}$ & $9,8 \mathrm{~b}$ \\
$\mathrm{Mg}$ & $3,8 \mathrm{~d}$ & $8,6 \mathrm{a}$ & $5,2 \mathrm{bc}$ & $4,7 \mathrm{~cd}$ & $4,6 \mathrm{~cd}$ & $6,1 \mathrm{~b}$ & $5,9 \mathrm{~b}$ & $6,2 \mathrm{~b}$ \\
$\mathrm{~S}$ & $6,1 \mathrm{a}$ & $3,3 \mathrm{c}$ & $3,7 \mathrm{bc}$ & $4,0 \mathrm{bc}$ & $3,5 \mathrm{bc}$ & $3,7 \mathrm{bc}$ & $4,3 \mathrm{~b}$ & $4,0 \mathrm{bc}$ \\
\hline
\end{tabular}

${ }^{(1)}$ Médias seguidas pela mesma letra, na linha, não diferem estatisticamente, pelo teste de Tukey $(0,05)$.

TABELA 5. Teores de macronutrientes na raiz da planta de pimentão no transplantio: (0); 20; 40; 60; $80 ; 100 ; 120$ e 140 dias após o transplantio de mudas.

\begin{tabular}{ccccccccc}
\hline Nutriente/ & 0 & 20 & 40 & 60 & 80 & 100 & 120 & 140 \\
\cline { 2 - 8 } Tempo & \multicolumn{7}{c}{$\mathrm{g} \mathrm{kg}^{-1}$} \\
\hline $\mathrm{N}$ & $18,0 \mathrm{e}(1)$ & $30,0 \mathrm{a}$ & $27,3 \mathrm{ab}$ & $18,5 \mathrm{e}$ & $20,8 \mathrm{de}$ & $24,8 \mathrm{bc}$ & $21,8 \mathrm{cde}$ & $23,3 \mathrm{~cd}$ \\
$\mathrm{P}$ & $7,6 \mathrm{a}$ & $2,8 \mathrm{~b}$ & $2,4 \mathrm{c}$ & $1,0 \mathrm{~d}$ & $1,1 \mathrm{~d}$ & $2,1 \mathrm{c}$ & $2,2 \mathrm{c}$ & $2,3 \mathrm{c}$ \\
$\mathrm{K}$ & $46,0 \mathrm{a}$ & $45,0 \mathrm{a}$ & $30,5 \mathrm{~b}$ & $0,5 \mathrm{e}$ & $10,0 \mathrm{~d}$ & $22,0 \mathrm{c}$ & $15,0 \mathrm{~d}$ & $14,5 \mathrm{~d}$ \\
$\mathrm{Ca}$ & $6,0 \mathrm{e}$ & $7,0 \mathrm{de}$ & $8,0 \mathrm{bcd}$ & $7,3 \mathrm{~cd}$ & $8,8 \mathrm{ab}$ & $7,3 \mathrm{~cd}$ & $8,3 \mathrm{bc}$ & $9,8 \mathrm{a}$ \\
$\mathrm{Mg}$ & $3,3 \mathrm{c}$ & $4,6 \mathrm{~b}$ & $2,5 \mathrm{~cd}$ & $0,2 \mathrm{e}$ & $1,7 \mathrm{~d}$ & $5,5 \mathrm{ab}$ & $5,0 \mathrm{ab}$ & $5,9 \mathrm{a}$ \\
$\mathrm{S}$ & $2,9 \mathrm{bc}$ & $3,5 \mathrm{~b}$ & $4,3 \mathrm{a}$ & $1,6 \mathrm{~d}$ & $2,4 \mathrm{~cd}$ & $3,5 \mathrm{ab}$ & $3,2 \mathrm{bc}$ & $3,3 \mathrm{~b}$ \\
\hline
\end{tabular}

${ }^{(1)}$ Médias seguidas pela mesma letra, na linha, não diferem estatisticamente, pelo teste de Tukey $(0,05)$.

Com os resultados apresentados na Tabela 6, observa-se que o macronutriente que alcançou a maior concentração na planta de pimentão, em todo o ciclo estudado da cultura, foi o potássio, com média de $39,9 \mathrm{~g} \mathrm{~kg}^{-1}$ de matéria seca, do transplantio até 140 DAT, seguido pelo nitrogênio, com média de 28,3 $\mathrm{g} \mathrm{kg}^{-1}$, cálcio com $12,8 \mathrm{~g} \mathrm{~kg}^{-1}$, magnésio com $5,9 \mathrm{~g} \mathrm{~kg}^{-1}$, enxofre com 4,1 $\mathrm{g} \mathrm{kg}^{-1}$ e o fósforo com 3,7 $\mathrm{g} \mathrm{kg}^{-1}$. Nota-se, nos resultados (Figura 1), que, em média, do transplantio até 140 DAT, o potássio contribuiu com $42,17 \%$ da concentração total de macronutrientes na planta de pimentão como um todo, seguido pelo nitrogênio com 29,89\%, cálcio com 13,47\%, magnésio com $6,23 \%$, enxofre com 4,28\% e o fósforo com 3,96\%. SANTOS (2001) achou as seguintes concentrações de macronutrientes para a planta de pimentão (híbrido Elisa), aos $84 \mathrm{DAT}$, fertirrigada, em $\mathrm{g} \mathrm{kg}^{-1}: 38,3$ de $\mathrm{N} ; 1,9$ de P; 47,6 de K; 19,4 de Ca; 6,9 de $\mathrm{Mg}$ e 3,6 de S. O mesmo autor encontrou, para outro híbrido (Magali R), aos 84 DAT, as seguintes concentrações de macronutrientes para a planta de pimentão, em g kg${ }^{-1}: 35,4$ de N; 1,8 de P; 42,9 de K; 21,4 de Ca; 6,2 de Mg e 3,4 de S.

Observa-se, neste experimento, que o nitrogênio obteve maior concentração na planta, o que representou acréscimo de $52 \%$ a mais em sua concentração, aos 40 DAT, em relação ao tempo 0. Observou-se que o fósforo, na planta de pimentão, assim como na raiz, no caule e na folha, foi o único nutriente que obteve diferença significativa no tempo $0\left(10,7 \mathrm{~g} \mathrm{~kg}^{-1}\right)$ em relação à menor concentração encontrada, que foi aos 80 DAT $\left(1,6 \mathrm{~g} \mathrm{~kg}^{-1}\right)$, ou seja, o fósforo, na planta de pimentão, perdeu $85,05 \%$ 
de sua concentração aos 80 DAT, tomando-se como base o tempo 0. Na Figura 1, apresenta-se a composição percentual dos macronutrientes na planta de pimentão ao longo do ciclo, em função dos intervalos de coleta, notando-se acréscimo da concentração do nitrogênio no período analisado e decréscimo do potássio.

TABELA 6. Teores de macronutrientes na planta de pimentão, como um todo, no transplantio: (0); 20; $40 ; 60 ; 80 ; 100 ; 120$ e 140 dias após o transplantio de mudas.

\begin{tabular}{ccrrrrrrr}
\hline Nutriente/ & 0 & 20 & 40 & 60 & 80 & 100 & 120 & 140 \\
\cline { 2 - 8 } Tempo & \multicolumn{7}{c}{$\mathrm{g} \mathrm{kg}^{-1}$} \\
\hline $\mathrm{N}$ & $18,0 \mathrm{e}(1)$ & $34,0 \mathrm{~b}$ & $37,5 \mathrm{a}$ & $27,0 \mathrm{~d}$ & $26,8 \mathrm{~d}$ & $25,8 \mathrm{~d}$ & $27,3 \mathrm{~cd}$ & $30,0 \mathrm{c}$ \\
$\mathrm{P}$ & $10,7 \mathrm{a}$ & $4,0 \mathrm{~b}$ & $3,1 \mathrm{c}$ & $2,1 \mathrm{de}$ & $1,6 \mathrm{e}$ & $2,4 \mathrm{~d}$ & $3,0 \mathrm{c}$ & $3,1 \mathrm{c}$ \\
$\mathrm{K}$ & $49,0 \mathrm{~b}$ & $57,0 \mathrm{a}$ & $50,3 \mathrm{~b}$ & $35,5 \mathrm{c}$ & $32,8 \mathrm{~cd}$ & $32,0 \mathrm{~cd}$ & $34,0 \mathrm{c}$ & $28,8 \mathrm{~d}$ \\
$\mathrm{Ca}$ & $14,0 \mathrm{bc}$ & $18,0 \mathrm{a}$ & $14,8 \mathrm{~b}$ & $12,0 \mathrm{~d}$ & $9,8 \mathrm{e}$ & $9,3 \mathrm{e}$ & $11,5 \mathrm{~d}$ & $12,8 \mathrm{~cd}$ \\
$\mathrm{Mg}$ & $5,0 \mathrm{~cd}$ & $9,0 \mathrm{a}$ & $7,2 \mathrm{~b}$ & $5,0 \mathrm{~cd}$ & $4,6 \mathrm{~d}$ & $5,1 \mathrm{~cd}$ & $5,7 \mathrm{c}$ & $5,7 \mathrm{c}$ \\
$\mathrm{S}$ & $5,2 \mathrm{a}$ & $4,0 \mathrm{c}$ & $4,9 \mathrm{ab}$ & $3,6 \mathrm{~cd}$ & $3,1 \mathrm{e}$ & $3,2 \mathrm{de}$ & $3,9 \mathrm{c}$ & $4,6 \mathrm{~b}$ \\
\hline (1)
\end{tabular}

(1) Médias seguidas pela mesma letra, na linha, não diferem estatisticamente, pelo teste de Tukey $(0,05)$.

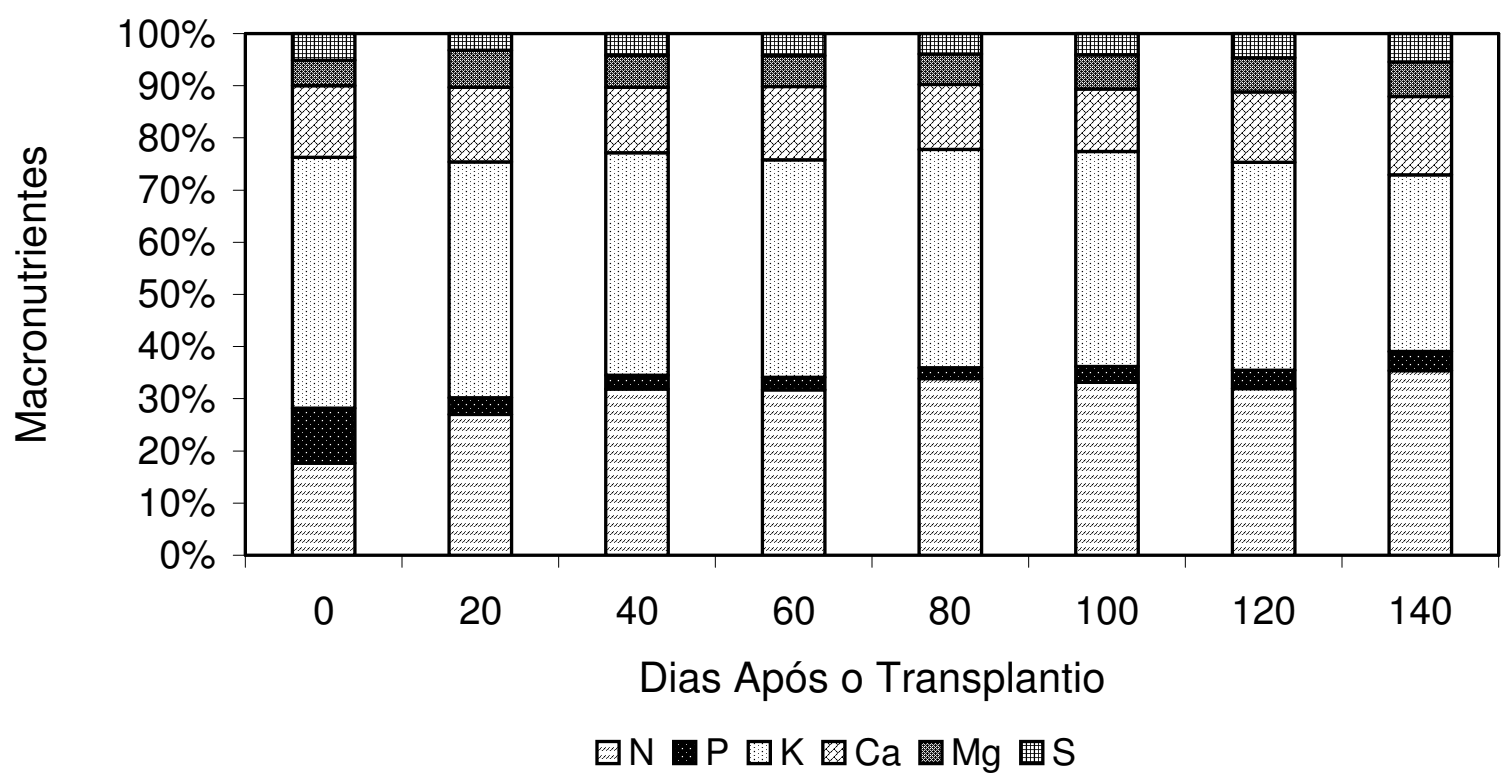

FIGURA 1.Distribuição dos teores totais, em percentagem, de macronutrientes na planta de pimentão, no transplantio: (0); 20; 40; 60; 80;100; 120 e 140 dias após o transplantio de mudas.

Os resultados obtidos permitem melhor monitoramento do estado nutricional da planta de pimentão, visando ao manejo adequado da aplicação de fertilizantes via água de irrigação. Segundo GUPTA (2001), quanto maior a capacidade da parte da planta em acumular um nutriente, maiores serão as diferenças na concentração desse nutriente em resposta a taxas variáveis de adubação; as partes da planta que acumularam as maiores quantidades de nutrientes durante o estádio metabólico ativo de crescimento são, em geral, as mais adequadas para amostragem, visando a determinar o estado nutricional das culturas. Segundo os dados obtidos neste experimento sob fertirrigação, a folha da planta de pimentão confirmou ser o órgão que melhor se enquadra nesses termos. No entanto, observase a necessidade de mais estudos que mostrem não só os teores adequados de nutrientes para a folha, mas também como coletar essas folhas, quais folhas da planta coletar e qual o melhor momento de coleta segundo o sistema de condução da cultura. TRANI \& RAIJ (1996) recomendam que se realize 
acompanhamento do estado nutricional das plantas por meio da análise foliar para verificar o nível de nutrientes na planta.

\section{CONCLUSÕES}

Verificou-se a seguinte ordem de concentração de macronutrientes no caule, folha e em toda a planta de pimentão (híbrido Elisa) sob fertirrigação: $\mathrm{K}>\mathrm{N}>\mathrm{Ca}>\mathrm{Mg}>\mathrm{S}>\mathrm{P}$; já a concentração de macronutrientes na raiz segue a seguinte ordem: $\mathrm{N}>\mathrm{K}>\mathrm{Ca}>\mathrm{Mg}>\mathrm{S}>\mathrm{P}$; no fruto, a ordem de concentração de macronutrientes foi: $\mathrm{K}>\mathrm{N}>\mathrm{Ca}>\mathrm{P}>\mathrm{S}>$.

O órgão da planta de pimentão que possui a maior concentração de macronutrientes sob fertirrigação é a folha, sendo, portanto, o órgão recomendado para análise de teor de macronutrientes, tanto na verificação de deficiência como na de toxidade.

\section{AGRADECIMENTOS}

À Fundação de Amparo à Pesquisa do Estado de São Paulo (FAPESP), pelo apoio financeiro; ao professor Roberto Lyra Villas Bôas, pela orientação, e aos funcionários do Departamento de Recursos Naturais - Ciência do Solo, que colaboraram para a execução do trabalho.

\section{REFERÊNCIAS}

BATAGLIA, O.C. Análise química de plantas. In: FERREIRA, M.E.; CRUZ, M.C.P. (Eds.). Macronutrientes na agricultura. Piracicaba: POTAFOS/CNPq, 1991. p.289-308.

COELHO, A.M. Fertigação. In: COSTA, E.F.; VIEIRA, R.F.; VIANA, P.A. (Eds.). Quimigação. Brasília: EMBRAPA-SPI, 1994. p.201-28.

FRIZZONE, J.A.; BOTREL, T.A.; DOURADO NETO, D. Aplicação de fertilizantes via água de irrigação. Piracicaba: Escola Superior de Agricultura "Luiz de Queiroz", USP, 1994. 35 p. (Série Didática, 8).

FURLANI, A.M.C.; FURLANI, P.R.; BATAGLIA, O.C.; HIROCE R.; GALLO, J.R; BERNARDI, J.B; FORNASIER, J.B.; CAMPOS, H.R. Composição mineral de diversas hortaliças. Bragantia, Campinas, v.37, n.1, p.33-44, 1978.

GUPTA, U.C. Macronutrientes e elementos tóxicos em plantas e animais. In: FERREIRA, M.E.; CRUZ, M.C.P.; RAIJ, B. Van; ABREU, C.A. (Eds.). Micronutrientes e elementos tóxicos na agricultura. Jaboticabal: POTAFOS/CNPq/FAPESP, 2001. p.13-41.

MAGALHÃES, J.R. Diagnose de desordens nutricionais em hortaliças. Brasília: EMBRAPA/DPU, 1988. 64 p. (Documentos, 1).

MALAVOLTA, E. Elementos de nutrição mineral de plantas. São Paulo: Agronômica Ceres, 1993. $251 \mathrm{p}$.

MALAVOLTA, E.; VITTI, G.C.; OLIVEIRA, S.A. Avaliação do estado nutricional de plantas: princípios e aplicações. 2.ed. Piracicaba: POTAFOS, 1997. 319 p.

MARSCHNER, H. Mineral nutrition of higher plants. $2^{\text {nd }}$ ed. New York: Academic Press, 1995. 889 p.

NASCIMENTO JUNIOR, N.A. Efeito da aplicação de $N$ e K via água de irrigação por gotejamento na cultura do pimentão em ambiente protegido. 1998. 92 f. Dissertação (Mestrado em Irrigação e Drenagem) - Faculdade de Ciências Agronômicas, Universidade Estadual Paulista, Botucatu, 1998. 
RAIJ, B.V. Princípios de correção e de adubação para mudas e para produção comercial. In:

SIMPÓSIO SOBRE NUTRIÇÃO E ADUBAÇÃO DE HORTALIÇAS, 1., 1990, Jaboticabal. Anais ... Piracicaba: POTAFOS, 1993. p.75-84.

SANTOS, R.F. Híbridos de pimentão cultivados em ambiente protegido e convencional, fertirrigado com doses de $N+K$, e avaliação da distribuição da evaporação. 2001. 165 f. Tese (Doutorado em Irrigação e Drenagem) - Faculdade de Ciências Agronômicas, Universidade Estadual Paulista, Botucatu, 2001.

SILVA, M.A.G. Efeito do nitrogênio e potássio na produção e nutrição do pimentão em ambiente protegido. 1998. 86 f. Tese (Doutorado em Solos e Nutrição Mineral de Plantas) - Escola Superior de Agricultura “Luiz de Queiroz”, Universidade de São Paulo, Piracicaba, 1998.

TRANI, P.E.; RAIJ, B.V. Hortaliças. In: RAIJ, B.V.; CANTARELLA, H.; QUAGGIO, J.A.;

FURLANI, A.M.C. Recomendações de adubação e calagem para o Estado de São Paulo. São Paulo: Fundação IAC, 1996. p.155-85. 